\title{
Labor market policies and equilibrium employment: Theory and application for Belgium *
}

\author{
Bruno Van der Linden ${ }^{\dagger}$ and Eric Dor ${ }^{\ddagger}$
}

February 20, 2001

\begin{abstract}
This paper is concerned with the general equilibrium effects of active labor market programs and the unemployment insurance system (the replacement ratio and the level of sanctions). It develops an equilibrium job matching model where active programs and the rate of sanctions have an ambiguous impact on the equilibrium employment rate. The model is simulated for Belgium. The simulations suggest that passive and active labor market policies do not have a substantial net impact on the employment rate.
\end{abstract}

Keywords: labor market policies; sanctions; equilibrium search model; matching function.

JEL classification : J63, J64, J65, J68.

${ }^{*}$ This paper presents research results of the Belgian Program on Interuniversity Poles of Attraction PAI P4/01 initiated by the Belgian State, Prime Minister's Office, Science Policy Programming. The scientific responsibility is assumed by the authors. We thank Henri Sneessens for useful comments.

${ }^{\dagger}$ Fonds National de la Recherche Scientifique and Institut de Recherches Economiques et Sociales, Département des Sciences Economiques, Université Catholique de Louvain. Email : vanderlinden@ires.ucl.ac.be.

${ }^{\ddagger}$ Université catholique de Lille (FLSE, IESEG, LABORES-CNRS) and Université catholique de Louvain (Institut de Recherches Economiques et Sociales). Email: e.dor@ieseg.fupl.asso.fr 


\section{Introduction}

Heckman, LaLonde and Smith (1999) urge the use of general equilibrium methods to assess the effects of labor market programs, especially those with a large target population. Sharing this view, this paper first develops an empirically justified general equilibrium model of the labor market that distinguishes passive and active labor market policies (LMPs). Since the theoretical analysis often leads to ambiguous effects of these policies on employment, the paper also simulates the model.

A lot of research has been devoted to the analysis of the microeconomic influence of unemployment compensation systems and active labor market policies (ALMPs) (see Atkinson and Micklewright, 1991, Pedersen and Westergard-Nielsen, 1993, OECD, 1993, Calmfors, 1994, Katz and Krueger, 1995, Fay, 1996, for surveys). Much less effort, as argued by Calmfors and Lang (1993) and Heckman, LaLonde and Smith (1999), has been devoted to the measurement of the general equilibrium or macroeconomic effects of these labor market policies. Yet this literature is growing. We make here no pretense at a comprehensive survey. What follows is a selective and highly condensed review of some important contributions. First, some authors have tried to assess to what extent the economic position of the non participants is changed by the existence of a program. Abandoning the traditional approach of regressing employment among the non participants on a program indicator, Davidson and Woodbury (1993) use a partial equilibrium matching model to assess the effect of reemployment bonus programs on the ineligible workers. Surveys have also been used to measure this impact (see e.g. OECD, 1993, and Van der Linden, 1997a).

Second, some sophisticated general equilibrium analyses have been developed where the link between labor market policies and wage formation has been emphasized (see e.g. the theoretical papers of Holmlund and Lindén, 1993, Calmfors and Lang, 1993, 1995). Broadly speaking, two effects go in opposite directions : A direct effect of ALMPs (they are supposed to maintain effective labor-force participation) and an indirect one (these policies typically reduce the disutility of being laid off and this increases wage pressure; on the latter phenomenon, see also the recent empirical analysis of Forslund and Kolm, 2000). Mortensen and Pissarides (1999) develop and calibrate an equilibrium search model to compare European and US labor market institutions in the presence of skilledbiased technological shocks. To measure the impacts of a national tuition-reduction policy, Heckman, Lochner and Taber (1998) develop and simulate an overlapping-generations general equilibrium framework with endogenous wages for the various skills.

Third, there is a quite large econometric literature where typically a matching function or a Beveridge curve is augmented with some labor market policy indicators (see e.g. Haskel and Jackman, 1988, Jackman, Pissarides and Savouri, 1990, Edin and Holmlund, 1990, Boeri and Burda, 1996 and Dor, Van der Linden and Lopez-Novella, 1997). This approach is only based on the matching function and lacks good theoretical foundations. Moreover, this approach only provides an estimation of the parameters of interest conditional on the vacancy (or the unemployment-vacancy) level. Yet, the main message of the recent theoretical literature is that labor market policies can have important effects on this level. Furthermore, in many countries, the reliability of the vacancies registered by Employment Agencies is rather dubious. They are not necessarily representative of the actual number of vacancies in the economy.

These drawbacks motivate the current research effort. We first develop an equilibrium 
job search model that draws upon Pissarides (1990) and Holmlund and Lindén (1993). In this model, LMPs turn out to have clear-cut effects on tightness on the labor market. Van der Linden and Dor (2000) exploits this property in order to specify an econometric model for the exit rate out of unemployment (which is a monotonous transformation of tightness). The estimated parameters are in line with the effects predicted by the theoretical analysis. Moreover, the estimation results confirm that the net impact of LMPs can be very different as soon as the number of vacancies is endogenous. However, the direction of the effect of LMPs on the unemployment exit rate and the one on the employment rate can be different. For instance, Van der Linden and Dor (2000) conclude that the rate of training has a negative effect on the hiring rate of non-participants. Since the effect on participants turns out to be favorable (Cockx and Bardoulat, 1999), the net effect on employment remains an unsettled issue. This is typically also true for other LMPs. To throw light on the impact of LMPs on employment, this paper simulates the model. The calibration is based on information about structural parameters collected for Belgium.

As the lower part of Table 1 shows, Belgium is broadly characterized by relatively low poverty rates but also by persistent unemployment, a large share of long-term unemployment and rather poor employment performances. Among other things, Marimon and Zilibotti (1998) highlight that Belgium should have idiosyncratic characteristics that explain the latter. This paper is also a contribution towards a better understanding of these characteristics. We here only focus on LMPs. A more comprehensive analysis can be found in Van der Linden (1997b). As far as ALMPs are concerned, there is a long tradition in Belgium of direct job creation for the unemployed, also called 'relief jobs' (see Table 1). The effort put into training has substantially increased but is still relatively lower than in many North-European countries. In comparison with the same countries, the replacement ratio is not particularly large. This ratio is fairly stable during the nineties. The rules which determine the disqualification for benefit are an other important feature of any compensation system. The rate of sanctions has sharply increased since 1990. Considering the nineties, this paper evaluates the impact on employment of a change in the replacement ratio, the rate of sanctions and the rate of entry into ALMPs.

The rest of the paper is organized as follows. Section 2 develops the model. Section 3 is devoted to the numerical simulation. Section 4 concludes the paper.

INSERT TABLE 1 APPROXIMATELY HERE.

\section{Job matching, labor market policies and equilibrium em- ployment}

\section{$2.1 \quad$ The model}

This section extends the equilibrium matching model to the case where four labor market states are distinguished: Insured unemployment, uninsured unemployment, programs and employment. The two first states are distinguished in order to emphasize the role of sanctions on the equilibrium employment rate. The third state identifies the formerly unemployed who are in active labor market programs ('relief jobs' or manpower training). So, the employment state should be understood as 'regular' employment.

This model draws upon Holmlund and Lindén (1993) who consider three sates : Unemployment, the programs and 'regular' employment. Assume a continuous-time setting. 
Due to various imperfections and heterogeneities that are not explicitly introduced in the model, the matching process is not instantaneous. So, the flow of hires, $H$, is a function of an indicator of the number of job-seekers, $S$, and the number of vacancies, $V$. The aggregate matching function writes : $H=h(S, V)$. It is assumed to be increasing, concave and homogeneous of degree $1 . S$ is not simply the sum of the number of insured unemployed, $U$, the number of program participants, $R$, and the number of uninsured unemployed, $X$. All these jobless workers are presumably not equivalent as far as the matching process is concerned. So, $S$ has to weight the various types of workers. To this end, each type of job-seeker receives a specific 'effectiveness parameters' $c_{i}, i=u, r, x$. These parameters do not only summarize differences in terms of search behavior. The perception of firms can be important, too (see e.g. the assumption of 'ranking' introduced by Blanchard and Diamond, 1994). Let us assume that the parameters $c_{i}$ 's are exogenous (we come back to that issue at the end of this section). With these notations, the number $S$ of job-seekers is $c_{u} U+c_{r} R+c_{x} X$ in 'efficiency units'.

The assumptions about the relative value of the $c_{i}$ 's should be clarified at the outset. If these parameters intend simply to capture the amount of time people devote to job search activities, we could expect that $c_{r} \leq c_{u}$. Yet, remember that the matching function implicitly encompasses the "heterogeneities frictions and information imperfections" (Pissarides, 1990, p. 3) present on the labor market. Program participants are arguably better informed about job opportunities than those in 'open unemployment'. For, as they are employed in public and non-profit organizations, they are presumably well aware of 'regular' job opportunities in these institutions. Similarly, the trainees can be in contact with firms (or are even trained by them). In addition, there is some evidence that training schemes improve human capital or signal more productive workers. So, our preferred assumption is $c_{r} \geq c_{u}$ but we keep aware that the alternative assumption could be relevant, too.

The assumption about $c_{x}$ is also controversial. The uninsured unemployed could reject less offers because their reservation wage must be lower or they could search more intensively. However, there is a growing evidence that the unemployed turn down very few offers (see e.g. Devine and Kiefer, 1991). Moreover, it has been argued that compared to non-claimants "benefit claimants maintain a closer attachment to the labour market and appear more able to prolong search effort" (Wadsworth, 1991). Furthermore, in our model, the individuals on which sanctions are imposed are on average de facto unemployed for a longer duration than the insured unemployed. Then discouragement and/or a ranking of job-applicants according to their unemployment duration can explain why their effectiveness parameter is lower (see Calmfors and Lang, 1995, in a related context). For these various reasons, we adopt the assumption $c_{u}>c_{x}>0$ but keep in mind the alternative assumption, too.

The labor force is made of an exogenous number $L$ of individuals $(L \equiv E+U+X+R$, where $E$ denotes 'regular' employment). $e, u, x$ and $r$ denote the rates obtained by dividing the levels by $L$ (e.g. $e \equiv \frac{E}{L}$ ). Let $\theta \equiv \frac{V}{S} . \quad \theta$ is a measure of the tightness of the labor market. The rate at which vacant jobs become filled is $q(\theta) \equiv H / V=h\left(\frac{1}{\theta}, 1\right), q^{\prime}(\theta)<0$. An 'efficient job-seeker' moves into employment according to a Poisson process with rate $\alpha(\theta) \equiv \frac{h(S, V)}{S}=\theta q(\theta)$, with $\alpha^{\prime}(\theta)>0$. Figure 1 summarizes the flows between the four states. The arrival rate of job offers is $c_{u} \alpha$ for an insured unemployed worker, $c_{x} \alpha$ for an uninsured unemployed and $c_{r} \alpha$ for a program participant. As will soon be clear, these offers are accepted. Each match in the regular segment is assumed to end at an 
exogenous rate $\phi$. Any worker whose job is terminated is assumed to be eligible for UI. ${ }^{1}$ To enter a program, a jobless worker has to transit into the insured unemployed state. This assumption fits the Belgian rules rather well. $\gamma$ denotes the exogenous arrival rate of program offers. A program ends at an exogenous rate $\lambda$. It is plausible to assume that $\lambda \geq \phi .{ }^{2}$ Finally, there is a limited duration of entitlement to UI. UI recipients have their benefit terminated at an exogenous rate $\pi$. In that case, they are entitled to a (lower) assistance benefit for an indefinite duration. Once UI benefit is exhausted, a worker must be hired before he becomes eligible again. In accordance with stylized facts in Belgium, uninsured unemployed have no access to programs. ${ }^{3}$

\section{INSERT FIGURE 1 APPROXIMATELY HERE.}

In a steady state, the flows between the four states are such that $e, u, x$ and $r$ are constant. These conditions lead to the following expressions :

$$
\begin{gathered}
\left(c_{r} \alpha(\theta)+\lambda\right) r=\gamma u \\
\phi(1-u-r-x)=\alpha(\theta)\left(c_{u} u+c_{r} r+c_{x} x\right) \\
c_{x} \alpha(\theta) x=\pi u
\end{gathered}
$$

Equations (1), (2), (3) and the identity $e \equiv 1-u-r-x$ determine $e, u, x$ and $r$ as a function of $\theta$. If $\Delta \equiv\left[\left(c_{u} \alpha(\theta)+\pi+\phi\right)\left(c_{r} \alpha(\theta)+\lambda\right)+\gamma\left(c_{r} \alpha(\theta)+\phi\right)\right] c_{x} \alpha(\theta)+\phi \pi\left(c_{r} \alpha(\theta)+\lambda\right)$ the following expressions define $e, u, x$ and $r$ :

$$
\begin{gathered}
e=\left[\left(c_{u} \alpha(\theta)+\pi\right)\left(c_{r} \alpha(\theta)+\lambda\right)+\gamma c_{r} \alpha(\theta)\right] c_{x} \alpha(\theta) \Delta^{-1}, \\
u=\phi c_{x} \alpha(\theta)\left(c_{r} \alpha(\theta)+\lambda\right) \Delta^{-1} \\
x=\phi \pi\left(c_{r} \alpha(\theta)+\lambda\right) \Delta^{-1}, \\
r=\phi \gamma c_{x} \alpha(\theta) \Delta^{-1} .
\end{gathered}
$$

\footnotetext{
${ }^{1}$ Since it will turn out that workers have no incentive to quit, $\phi$ should be interpreted as an exogenous firing rate. It is assumed that laid-off workers receive UI benefits. This assumption could be relaxed at the cost of some additional complexity, which would not really further our present purpose. In the Belgian context which underlies this analysis, only $5 \%$ of claimants are judged to be ineligible to UI benefits during the nineties.

${ }^{2}$ Casual observations for Belgium indicate that training schemes typically last a few months. The duration of relief job spells seems to be very heterogeneous. Some of them have a clear-cut duration (around a year), others are not necessarily very different from regular jobs. As far as the latter are concerned, Cockx, Van der Linden and Karaa (1998) analyze a sample of Belgian employees hired after a spell in unemployment. The first quartile duration of a worker with average characteristics is estimated to be 14 months, suggesting a quite large average duration of completed job spells. Hence, on average, the assumption $\lambda \geq \phi$ should be satisfied.

${ }^{3}$ Other papers have introduced sanctions or a limited duration of entitlement in general equilibrium models. See Atkinson (1995), Ljungqvist and Sargent (1995), Fredriksson and Holmlund (1998), Cahuc and Lehmann (2000) and Boone and van Ours (2000).
} 
These relationships are the first basic component of this model. It can be checked that the employment rate is an upward-sloping function of tightness $\theta$.

$\theta$ is determined by the behavior of firms and workers. Assume that firms are homogeneous and that each of them has only one job. The firm's discounted expected return from an occupied (respectively, vacant) job is denoted $\Pi_{e}$ (respectively $\Pi_{v}$ ). Let $\delta$ be the discount rate of the workers and the firm, $y$ the constant marginal product of a filled vacancy, $w_{c}$ the cost of labor and $k$ the fixed cost of a vacant job per unit of time ( $k$ captures the cost involved in posting a vacancy, searching for applicants and selecting them). Still assuming a steady state, $\Pi_{e}$ and $\Pi_{v}$ satisfy the following conditions :

$$
\begin{gathered}
\delta \Pi_{e}=y-w_{c}+\phi\left(\Pi_{v}-\Pi_{e}\right), \\
\delta \Pi_{v}=-k+q(\theta)\left(\Pi_{e}-\Pi_{v}\right) .
\end{gathered}
$$

In equilibrium, vacancies are opened as long as they yield a positive expected return. Therefore, the equilibrium condition for the supply of vacancies is $\Pi_{v}=0$. Using (8) and (9), this equilibrium condition can be rewritten as follows:

$$
y=w_{c}+\frac{(\delta+\phi) k}{q(\theta)} .
$$

This relationship, the 'vacancy-supply curve', is the second basic component of this model. This optimality condition says that the marginal product of a filled vacancy should be equal to the wage cost plus the expected capitalized value of the hiring cost. Conditional on $y, \delta, \phi$ and $k$, equality (10) defines a downward-sloping relationship between the wage cost and $\theta$.

Assume risk-neutral workers. Let $V_{e}, V_{u}, V_{x}$ and $V_{r}$ denote the present-discounted value of the expected income stream of, respectively, an employed worker, an insured unemployed, an uninsured unemployed and a program participant. Assume that payroll taxes are levied at a rate $t: w_{c} \equiv w(1+t)$. In equilibrium, where the wage rate, $w$, is the same everywhere, the four expected lifetime incomes can be defined by the following equalities :

$$
\begin{gathered}
\delta V_{e}=w+\phi\left(V_{u}-V_{e}\right) \\
\delta V_{u}=b_{u}+c_{u} \alpha\left(V_{e}-V_{u}\right)+\gamma\left(V_{r}-V_{u}\right)+\pi\left(V_{x}-V_{u}\right), \\
\delta V_{r}=b_{r}+c_{r} \alpha\left(V_{e}-V_{r}\right)+\lambda\left(V_{u}-V_{r}\right), \\
\delta V_{x}=s+c_{x} \alpha\left(V_{e}-V_{x}\right),
\end{gathered}
$$

where $b_{u}, b_{r}$ and $s$ denote respectively the unemployment benefit, the benefit/earnings of program participants and the assistance benefit. We assume that these benefits are proportional to wages. Let $\rho_{u}, \rho_{r}$ and $\sigma$ be the corresponding replacement ratios $\left(\rho_{u} \equiv \frac{b_{u}}{w}\right.$, 
$\rho_{r} \equiv \frac{b_{r}}{w}$ and $\left.\sigma \equiv \frac{s}{w}\right)$. The choice of these benefit levels has to be incentive compatible. It can be checked that $V_{e}>V_{r}>V_{u}>V_{x}$ if $c_{r} \geq c_{u}>c_{x}>0$ and $1>\rho_{r} \geq \rho_{u} \geq \sigma \geq 0{ }^{4}$

If a job terminates, the firm and the worker will have to engage in a costly search process before they can meet another partner. This gives rise to a rent that has to be shared. The wage rate is derived from the maximization of the following Nash product $:^{5}$

$$
\max _{w}\left(V_{e}-V_{u}\right)^{\beta}\left(\Pi_{e}-\Pi_{v}\right)^{1-\beta},
$$

with $0<\beta<1$. The first-order condition can be written as :

$$
y-w_{c}=\frac{1-\beta}{\beta}\left(V_{e}-V_{u}\right)(\delta+\phi)(1+t) .
$$

The negotiated wage is a negative function of the difference in expected value between employment and insured unemployment. One has to solve equations (11) to (14), to substitute the difference $V_{e}-V_{u}$ into (16). This difference can be written as $V_{e}-V_{u}=$ $w f(\alpha(\theta), Z)$ where $f(\alpha(\theta), Z)$ is defined as :

$$
\frac{\left(\delta+c_{x} \alpha\right)\left[\left(1-\rho_{u}\right)\left(\delta+c_{r} \alpha+\lambda\right)+\gamma\left(1-\rho_{r}\right)\right]+\pi\left(\delta+c_{r} \alpha+\lambda\right)(1-\sigma)}{\left(\delta+c_{x} \alpha\right)\left[\left(\delta+c_{r} \alpha+\lambda\right)\left(c_{u} \alpha+\phi+\delta\right)+\gamma\left(c_{r} \alpha+\phi+\delta\right)\right]+\pi\left(\delta+c_{r} \alpha+\lambda\right)\left(\phi+\delta+c_{x} \alpha\right)},
$$

with $\alpha=\alpha(\theta)$ and $Z \equiv\left(\delta, c_{u}, c_{x}, c_{r}, \gamma, \lambda, \phi, \pi, \rho_{u}, \rho_{r}, \sigma\right)^{\prime}$. It can be checked that $\frac{\partial f}{\alpha}<0$ if $\phi \leq \lambda$ and $1>\rho_{r} \geq \rho_{u} \geq \sigma \geq 0$. Combining (10), (16) and (17) leads to :

$$
w_{c}=\frac{\beta k}{(1-\beta) q(\theta) f(\alpha(\theta), Z)} .
$$

This expression defines a 'wage-setting curve' relating the wage cost to $\theta$. This curve is upward-sloping if $k$ is unrelated to $w_{c}$. Figure 2 illustrates the three equilibrium relationships (4),(10) and (18) when $k$ is a constant. The lower segment shows the steady state relationship (4) between the employment rate $e$ and tightness $\theta$. The upper segment shows the upward-sloping wage-setting curve (18) and the downward-sloping vacancy supply curve (10). From (10) and (18), the payroll tax rate does not influence the wage cost nor the equilibrium level of tightness $\theta$. Hence, given (4), the payroll tax rate does not influence the employment rate either. ${ }^{6}$

\section{INSERT FIGURE 2 APPROXIMATELY HERE.}

\footnotetext{
${ }^{4}$ If $c_{r}$ was lower than $c_{u}$, the incentive compatibility constraints would require additional restrictions upon $\rho_{r}-\rho_{u}$ and $\rho_{r}-\sigma$. If $V_{r}<V_{u}$, it could still be argued that the public employment services can actually impose the acceptance of a relief job or a training offer by the unemployed. However, if $V_{r}$ is lower than $V_{u}$ because $c_{r}$ is low compared to $c_{u}$ (and $c_{x}$ ), the notes under Table 2 will illustrate that increasing the rate of entry into programs can have a negative impact on the equilibrium employment rate. For similar reasons, restrictions should be imposed on $\rho_{u}-\sigma$ and $\rho_{r}-\sigma$ if $c_{x}$ was greater or equal to $c_{u}$.

${ }^{5}$ By assumption, wages can be renegotiated at any time. So, whatever his previous state on the labor market, the fallback level for a worker is the position of insured unemployment.

${ }^{6}$ This result is no more general as soon as individual working time and/or leisure time are added to the model.
} 


\subsection{Comparative statics}

In Table 2, we look at the effects of the 'labor market policies parameters' $\gamma, \lambda, \pi, \rho_{u}, \rho_{r}$ and $\sigma$ and the 'structural parameters' of this economy $c_{u}, c_{x}, c_{r}, \phi, \delta, k, \beta, y$. The second column gives the sign of the effect on the 'employment curve' (4). The third column is devoted to the 'wage-setting curve' (18). The fourth is concerned with the 'vacancy supply curve' (10). From the effects on the two latter curves, the influence on the equilibrium level of tightness $\theta$ is seen in the fifth column. This and the shift of the 'employment curve' (column 2) lead to the change in the equilibrium employment rate (the last column). Unambiguous conclusions are reached in the case of the replacement ratios. They only influence wage bargaining, in such a way that the higher the replacement ratio, the lower the employment rate. Table 2 shows that the net effect on the equilibrium employment rate of the other labor market policies is ambiguous under the assumptions $c_{r} \geq c_{u}>c_{x}>0$ and $1>\rho_{r} \geq \rho_{u} \geq \sigma \geq 0$. For instance, increasing the rate of participation into programs $(\gamma)$ has a favorable direct effect on the employment rate, given $\theta$. Yet, improved prospects in case of unemployment lead to an increase in the bargained wage cost. This indirect effect reduces the equilibrium vacancy-job searchers ratio $\theta$. Hence, the net effect cannot be signed unambiguously. The conclusion is the same in the case of an increase in the rate of sanctions, $\pi$, yet for opposite reasons. The indirect effect is now a reduction of the wage cost because the expected income stream is lower in case of unemployment. But the direct effect is unfavorable. Conditional on $\theta$, a higher $\pi$ means more uninsured unemployment (with worse employment opportunities) and less insured unemployed and trainees (with better employment opportunities). Some of the ambiguous net effects in Table 2 could be signed by assuming a relatively low value for $c_{r}$, a relatively high value for $c_{x}$ and sufficiently different replacement ratios. Then, raising $\gamma$ would unambiguously decrease the equilibrium unemployment rate and conversely raising $\pi$ would unambiguously boost the equilibrium employment rate. However, we have explained above why these assumptions are not the most plausible ones. Alternatively, the ambiguous net effects in Table 2 could be signed by a numerical simulations. The next section will develop such an approach.

\section{INSERT TABLE 2 APPROXIMATELY HERE.}

In Table 2, the structural parameters have typically a clear-cut net effect on the employment rate. Increasing the rate of job termination, the discount rate, the cost of opening vacancies or the relative bargaining power of the worker reduces the equilibrium employment rate. An improvement in the 'effectiveness parameters' $c_{u}, c_{x}$ or $c_{r}$ has on the contrary ambiguous effects on the employment rate. The direct effect is favorable, yet the indirect one leads to higher wages and a lower equilibrium value for $\theta$.

Up to now we have assumed that each of the exogenous structural parameters and labor market policy parameters could be modified without affecting the others. This is questionable. It is for instance often admitted that an increase in the rate of sanctions or a more limited duration of entitlement will enhance the probability that an unemployed person exits from unemployment to employment. Recent microeconometric evidence supporting this assertion can be found in e.g. Carling, Edin, Harkman and Holmlund (1996) and Abbring, van den Berg and van Ours (1999). Fredriksson and Holmlund (1998) develop a theoretical model similar to ours where search intensity is endogenous. They show that the equilibrium level of search of the insured unemployed increases with $\pi$ through an effect on $\theta$. So it could be argued that an increase in $\pi$ leads in a way or another to a 
higher parameter $c_{u}$. Moreover, Fredriksson and Holmlund (1998) show that the equilibrium level of search of the uninsured unemployed decreases with $\pi$ if the discount rate is sufficiently low. In these examples, the assumed interactions introduce more complexity. Combining the results summarized in Table 2 and these interactions does not allow to sign the net effect of those policy changes on the employment rate.

\section{A numerical simulation for Belgium}

The section aims at calibrating the model for Belgium in order to simulate the net effects of $\gamma$ and $\pi$ on the equilibrium employment rate $e$. Moreover, we intend to measure the magnitude of the negative effect of the replacement ratios on $e$. Only the impact of $\rho_{u}$ will be considered here.

\subsection{Calibration}

We take the month as the unit of time. As far as possible, the values of the parameters are based on observed data for the nineties. We choose 1997 as a reference. ${ }^{7}$ There are administrative data about the average level of benefit paid out to the unemployed and about assistance benefits. These data and the estimated average net wage allow to fix $\rho_{u}$ to 0.34 and $\sigma$ to 0.23 . The state $R$ measures participation in active labor market programs (merging relief jobs and manpower training). Those in training receive a benefit that is marginally higher than the unemployment benefit. On the contrary, those in relief jobs typically are paid the same wage as 'regularly' employed workers in similar occupations. On the basis of this information, we are able to estimate an average replacement ratio for those taking part to active programs: $\rho_{r}=0.65$. Published data also allow to fix the monthly sanction rate $\pi$ at 0.01 . The appendices of the OECD's Employment Outlook display the inflows into active labor programs. This information is exploited to set $\gamma=0.05$.

There are no reliable data on the rate of entry into unemployment $(\phi)$ nor about the rate at which active programs end $(\lambda)$. Nevertheless, there are administrative data about the number of full-time insured unemployed for less than three months. This information implies that $\phi$ should be larger than 0.013. Incomplete information about flows between training programs and insured unemployment suggest that $\lambda$ should be higher or equal to 0.04. These bounds are used below.

As many other papers, let us assume a Cobb-Douglas matching function. We take $h(S, V) \equiv C S^{0.6} V^{0.4}$, where $C$ is a parameter. These hypotheses are supported by previous empirical analyses at the aggregate level (see Petrongolo and Pissarides, 2000). Consequently, the hiring rate of any category $i, c_{i} \alpha(\theta)$ equals $c_{i} C \theta^{0.4}, \forall i \in\{u, r, x\} . C$ is therefore a scaling factor that allows to normalize $c_{u}$ to 1 . Parameters $C, c_{x}$ and $c_{r}$ are then chosen jointly with $\phi$ and $\lambda$ in the following way. First, we set $\delta=0.008 .{ }^{8}$ Second, we take the 1997 values of $E, X, U, R$ and $L$. According to administrative data, the corresponding rates are $e=0.835, u=0.125, r=0.03, x=0.01$. These values are plugged in equations (4) to (7) in order to find the value for $\theta$ and to fix parameters $\phi$ and $\lambda$. Doing so, we keep the following constraints in mind: $\phi>0.013$ and $\lambda>0.04$. Moreover,

\footnotetext{
${ }^{7}$ The years close to 1993 were deeply affected by the major recession of the nineties. The last years of this decade were clearly Van dresse a boom. Moreover, some of the data are then lacking.

${ }^{8}$ We also considered the value $\delta=0.004$ and found less reasonable parameters.
} 
plausible values for the (imperfectly observed) stock of vacancies are used as an additional qualitative target. It turns out that reasonable values for $\phi$ and $\lambda$ require that $c_{r}$ and $c_{x}$ be close to $c_{u}$. Henceforth, we take $c_{r}=1.05, c_{x}=0.95, \lambda=0.042, \phi=0.031, C=0.35$. With these parameters, $\theta=0.14$. The relative value for $c_{r}$ sounds plausible. Cockx and Bardoulat (1999) provide an unbiased estimator of the effect of training programs in the southern part of Belgium. For those who have completed the training scheme, they conclude that the selected average treatment effect is 1.6. The evidence about relief jobs is less robust. Ignoring selection on unobservables, Mahy (1994) concludes that participation in relief jobs has an unfavorable effect on the probability of entering 'regular jobs'. Since the share of trainees in the stock of participants in active programs is less than one-third, the relative value of $c_{r}$ is reasonable.

The vacant job costs per unit of time, $k$, are assumed to be proportional to the marginal product of a filled vacancy, $y$. Then, except for the wage rate, the major steady-state properties of the model are independent of the value of $y$. Let $\kappa \equiv \frac{k}{y}$. Then, combining (10) and (18), it can be checked that the equilibrium value of $\theta$ solves the following implicit equation :

$$
[q(\theta)-\kappa(\delta+\phi)] f(\alpha(\theta), Z)=\frac{\beta}{1-\beta} \kappa
$$

Taking $\theta=0.14$, this equation allows to fix the bargaining power $\beta$ as a function of $\kappa$. It turns out that only high values of $\kappa$ are compatible with plausible values of $\beta$. This phenomenon is not new (see Wasmer, 1999, and Mortensen and Pissarides, 1999, who introduce training costs in addition to screening costs). So, we assume $\kappa=1$. Then, $\beta=0.77$ solves (19).

\subsection{The response of the employment rate to labor market policy shocks}

For the values of the parameters adopted in the previous section, let us consider changes in the sanction rate $\pi$, the rate of entry into active programs $\gamma$ and the replacement ratio for the insured unemployed $\rho_{u}$. We only focus on the net impact on the employment rate $e$. The simulations throw light on three issues. From Section 2, we know that $\theta$ increases with $\pi$ and decreases with $\gamma$ and $\rho_{u}$. Under the hypothesis that $c_{x}<c_{u} \leq c_{r}$, the net effect of a rise in $\pi$ on the employment rate is however analytically ambiguous. In our numerical example, $c_{x}$ is only $5 \%$ lower than $c_{u}$. Whether such a small difference would be sufficient to compensate the effect on $\theta$ is a first interesting question. Second, $c_{r}$ is only $5 \%$ higher than $c_{u}$ : Is this sufficient to compensate the unfavorable effect of $\gamma$ on $\theta$ ? Finally, we know that the employment rate is a negative function of $\rho_{u}$. Yet, the strength of the relationship is an interesting issue.

As Figure 3 shows, large variations in the sanction rate $\pi$ only have a minor impact on tightness. This result is in accordance with the conclusions in Van der Linden and Dor (2000). With $c_{x} 5 \%$ lower than $c_{u}$, the net effect on employment is negligible. These conclusions clearly are at odds with micro-econometric evaluations of sanctions by Abbring, van den Berg and van Ours (1999). These authors found a large effect of sanctions on the exit rate of the treated. Clearly, if $c_{x}$ was sufficiently higher than $c_{u}$, our model would lead to qualitatively similar conclusions as those of Abbring, van den Berg and van Ours (1999). There is therefore a clear need for more microeconometric analyses of the effect of sanctions. 
Figure 4 is concerned with the impact of $\gamma$. Compared to the previous figure, the impact on equilibrium tightness is more substantial. Yet, even large shocks on $\gamma$ do not have a dramatic effect on $\theta$. Moreover, a small favorable effect on the participants (here, $\left.c_{r}=1.05\right)$ is sufficient to compensate this impact. The employment rate is indeed not much affected by $\gamma$.

The impact of the replacement ratio $\rho_{u}$ on $\theta$ is shown in Figure 5. Compared to the two previous cases, the sensitivity of $\theta$ with respect to $\rho_{u}$ appears to be more important. As expected, the net effect on $e$ is negative but the relative change is clearly not large. The intuition behind the latter result can be found in equation (4). The rate at which an 'efficient job-seeker' enters 'regular employment', $\alpha(\theta)$, is an increasing function of $\theta$ (with an elasticity of 0.4 ). This rate appears both in the numerator and the denominator of equation (4). Therefore, it should be expected that $e$ is less affected by $\rho_{u}$ than $\theta$.

\section{INSERT FIGURES 3, 4 AND 5 APPROXIMATELY HERE.}

\section{Conclusion}

There is a clear need for evaluation that deals with indirect effects of labor market policies on wages and other economic indicators. To face the challenge of a better integration between theory and empirical analysis, we have first developed a theoretical general equilibrium model of the labor market. In this model, the unemployment-vacancy ratio is endogenously determined by a set of structural and labor market policy parameters. By assumption, those who are in active programs have a better 'matching effectiveness' than the insured unemployed and the opposite holds for those who are sanctioned. The equilibrium job search model leads to the conclusion that policies that improve the intertemporal prospect of being unemployed lead to a wage-push effect and eventually to less vacancies per job-seeker (measured in efficiency units). However, most of the labor market policies have an ambiguous net effect on the equilibrium employment rate because policies that lead to more (less) vacancies also deteriorate (improve) the composition of the pool of those who search for a 'regular job' (i.e. an occupation which is not specifically created for the unemployed). Only the replacement ratio has a clear negative influence in this model. It has therefore been calibrated and shocks to various labor market policy indicators have been simulated.

The major conclusion of the simulations is that passive and active labor market policies would not have a substantial net impact on the employment rate. This conclusion holds for Belgium where the average 'matching effectiveness' of the insured unemployed, the uninsured unemployed and those in active programs apparently do not differ much. These minor differences are sufficient to compensate the net effects of the sanction rate and the rate of entry into active programs on wages and on the number of vacancies.

\section{References}

Abbring, J., G. van den Berg and J. van Ours (1999) "The effect of unemployment insurance sanctions on the transition rate from unemployment to employment". Working Paper mimeo, Department of Economics, University of Amsterdam and Tinbergen Institute, The Netherlands. 
Atkinson, A. (1995) Institutional features of unemployment insurance and the working of the labour market. In A. Atkinson, editor, Incomes and the Welfare State. Cambridge University Press, Cambridge.

Atkinson, A. and J. Micklewright (1991) "Unemployment compensation and labour market transitions : A critical review". Journal of Economic Literature, 191:1679-1727.

Blanchard, O. and P. Diamond (1994) "Ranking, unemployment duration,and wages". Review of Economic Studies, 61:417-434.

Boeri, T. and M. Burda (1996) "Active labour market policies, job matching and the Czech miracle". European Economic Review, 40:805-17.

Boone, J. and J. van Ours (2000) "Modeling financial incentives to get unemployed back to work". Working Paper 108, Institute for the Study of Labor (IZA), Bonn.

Cahuc, P. and E. Lehmann (2000) "Should unemployment benefits decrease with unemployment spell?" Journal of Public Economics, 77:135-153.

Calmfors, L. (1994) "Active labour market policy and unemployment: Framework for analysis of crucial design features". OECD Economic Studies, 22:7-52.

Calmfors, L. and H. Lang (1993) "Macroeconomic effects of active labour market programmes : The basic theory". Working Paper Seminar Paper 541, Institute for International Economic Studies, Stockholm University.

Calmfors, L. and H. Lang (1995) "Macroeconomic effects of active labour market programmes in a union wage-setting model". Economic Journal, 105:601-619.

Carling, K., P.-A. Edin, A. Harkman and B. Holmlund (1996) "Unemployment duration, unemployment benefits, and labor market programs in Sweden". Journal of Public Economics, 59:313-34.

Cockx, B. and I. Bardoulat (1999) "Vocational training : Does it speed up the transition rate out of unemployment?" Working Paper 9932, Institut de Recherches Economiques et Sociales, Department of Economics, Université Catholique de Louvain, Louvain-la-Neuve, Belgium.

Cockx, B., B. Van der Linden and A. Karaa (1998) "Active labour market policies and job tenure". Oxford Economic Papers, 50:685-708.

Davidson, C. and S. Woodbury (1993) "The displacement effect of reemployment bonus programs". Journal of labor Economics, 11:575-605.

Devine, T. and N. Kiefer (1991) Empirical labor economics. Oxford University Press, Oxford.

Dor, E., B. Van der Linden and M. Lopez-Novella (1997) "On labour market policies and aggregate unemployment outflows". Oxford Bulletin of Economics and Statistics, 59:109-131. 
Edin, P.-A. and B. Holmlund (1990) Unemployment, vacancies and labour market programmes: Swedish evidence. In F. Padoa Schioppa, editor, Mismatch and labour mobility. Cambridge University Press, Cambridge.

European-Commission (1997) Employment in Europe. Office for Official European Publications of the European Communities, Brussels, Luxemburg.

Fay, R. (1996) "Enhancing the effectiveness of active labour market policies: Evidence from programme evaluations in OECD countries". Working Paper 18, Labour market and social policy occasional papers, OECD, Paris.

Forslund, A. and A. Kolm (2000) "Active labour market policies and real-wage determination - Swedish evidence". Working Paper 2000:7, IFAU - Office of Labour Market Policy Evaluation, Uppsala, Sweden.

Fredriksson, P. and B. Holmlund (1998) "Optimal unemployment insurance in search equilibrium". Working Paper 2, Department of Economics, Uppsala University, Sweden. Journal of Labor Economics, forthcoming.

Haskel, J. and R. Jackman (1988) "Long-term unemployment in Britain and the effect of the Community Programme". Oxford Bulletin of Economics and Statistics, 50:379-408.

Heckman, J., R. LaLonde and J. Smith (1999) The economics and econometrics of active labor market programs. In O. Ashenfelter and D. Card, editors, Handbook of Labor Economics, Volume 3C. Elsevier Science Publisher (North-Holland), Amsterdam.

Heckman, J., L. Lochner and C. Taber (1998) "General equilibrium treatment effects: A study of tuition policy". American Economic Review, 88:381-386.

Holmlund, B. and J. Lindén (1993) "Job matching, temporary public employment, and equilibrium unemployment". Journal of Public Economics, 51:329-343.

Jackman, R., C. Pissarides and S. Savouri (1990) "Labour market policies and unemployment in the OECD". Economic Policy, 11:449-490.

Katz, L. and A. Krueger (1995) "What's working (and what's not). A summary of research on the economic impacts of employment and training programs". Working Paper, U.S. Department of Labor.

Ljungqvist, L. and T. Sargent (1995) "The Swedish unemployment experience". European Economic Review, 39:1043-1070.

Mahy, B. (1994) "Politiques et recherche d'emploi: Évaluation micro-économétrique". Reflets et perspectives de la vie économique, 23:87-102.

Marimon, R. and F. Zilibotti (1998) "Actual' versus 'virtual' employment in Europe. is Spain different?" European Economic Review, 42:123-153.

MET (1999) La politique fédérale de l'emploi: Rapport d'évaluation. Ministère fédéral de l'Emploi et du Travail, Rue Belliard 21, 1040 Brussels.

Mortensen, D. and C. Pissarides (1999) "Unemployment responses to 'skill-biased' technology shocks: The role of labour market policy". Economic Journal, 109:242-266. 
OECD (1993) Employment outlook. OECD, Paris.

Pedersen, P. and N. Westergard-Nielsen (1993) "Unemployment : A review of the evidence from panel data". OECD Economic Studies, 20:72-127.

Petrongolo, B. and C. Pissarides (2000) "Looking into the black box: A survey of the matching function". Working Paper mimeo, Centre for Economic Performance, London School of Economics, U.K.

Pissarides, C. (1990) Equilibrium unemployment theory. Basil Blackwell, Oxford.

Van der Linden, B. (1997a) "Effets des formations professionnelles et des aides à l'embauche : exploitation d'une enquête auprès d'employeurs belges". Economie et Prévision, 131:113-130.

Van der Linden, B. (1997b) (Ed.), Chômage: réduire le fracture. De Boeck-Université, Paris, Bruxelles.

Van der Linden, B. and E. Dor (2000) "The net effect of unemployment benefits, sanctions and training on aggregate unemployment outflows". Working Paper 2000-20, Institut de Recherches Economiques et Sociales, Departement of Economics,Université Catholique de Louvain, Louvain-la-Neuve, Belgium.

Wadsworth, J. (1991) "Unemployment benefits and search effort in the UK labour market". Economica, 58:17-34.

Wasmer, E. (1999) "Screening vs. training in equilibrium search models". Working Paper mimeo, ECARES, Université Libre de Bruxelles, Belgium. 


\begin{tabular}{|c|c|c|c|c|c|c|c|c|c|}
\hline Programs (expenditure) & 1985 & 1990 & 1991 & 1992 & 1993 & 1994 & 1995 & 1996 & 1997 \\
\hline Public employment services & 0.17 & 0.18 & 0.19 & 0.19 & 0.22 & 0.23 & 0.23 & 0.20 & 0.19 \\
\hline Labor market training & 0.20 & 0.21 & 0.22 & 0.24 & 0.27 & 0.29 & 0.29 & 0.30 & 0.29 \\
\hline Direct job creation $(*)$ & 0.79 & 0.55 & 0.51 & 0.52 & 0.51 & 0.54 & 0.54 & 0.53 & 0.47 \\
\hline Subsidies to 'regular employment' & 0.04 & 0.05 & 0.02 & 0.02 & 0.03 & 0.09 & 0.16 & 0.28 & 0.15 \\
\hline Total active measures & 1.35 & 1.23 & 1.21 & 1.23 & 1.25 & 1.37 & 1.42 & 1.50 & 1.29 \\
\hline Average replacement ratio $\left({ }^{* *}\right)$ & 40.0 & 35.4 & 34.5 & 33.9 & 34.6 & 33.9 & 34.0 & 34.9 & 34.3 \\
\hline Annual frequency of sanctions $(\ddagger)$ & 5.7 & 8.4 & 14.4 & 11.4 & 16.4 & 12.5 & 12.3 & 14.7 & 12.0 \\
\hline 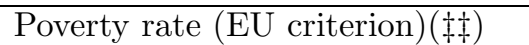 & 6.0 & & & 6.7 & & & & & 6.9 \\
\hline Employment rate $(\dagger)$ & 53.1 & 54.7 & 56.1 & 56.8 & 56.3 & 56.0 & 56.6 & 56.6 & 57.3 \\
\hline Unemployment rate & 10.3 & 6.7 & 6.6 & 7.3 & 8.9 & 10.0 & 9.9 & 9.7 & 9.2 \\
\hline Long-term unemployment $(\dagger \dagger)$ & 69.2 & 68.2 & 62.8 & 59.0 & 52.9 & 58.3 & 62.4 & 61.2 & 60.5 \\
\hline
\end{tabular}

Table 1. Expenditures on active labor market programs (\% of GDP) and basic labor market indicators (\%): Belgium.

Source: Expenditures on labor market programs: MET (1999); Labor market indicators : European-Commission (1997).

$\left.{ }^{*}\right)$ public or non profit sectors : 'relief jobs'.

(**) In \%. The replacement ratio measures the ratio between the average unemployment benefit and the average net wage (both measured per head). See the appendix of Van der Linden and Dor (2000).

( $\ddagger$ In $\%$. The numerator measures the annual flow of full-time insured unemployed who are no more entitled to unemployment benefits. The series of disqualifying reasons include voluntary separation from work, unavailability for a job or an active labor market policy, refusal of a suitable job offer, misconduct during unemployment (e.g. undeclared paid work), non compliance with the administrative rules and unemployment for an 'excessive' duration. The denominator is the stock of able-bodied unemployed (entitled to unemployment benefits) measured at the end of June. See the appendix of Van der Linden and Dor (2000).

(†) Centrum voor Sociaal Beleid, UFSIA, Universiteit Antwerpen, Belgium.

(†) $\%$ of working age population.

(††) Share in the stock (in \%). 


\begin{tabular}{|c|c|c|c|c|c|}
\hline parameter & $e(\theta)^{*}$ & wage curve* & vacancy supply* & equilibrium $\theta^{* *}$ & equilibrium $e^{* *}$ \\
\hline$\gamma$ & $+^{\circ}$ & $+^{\circ}$ & 0 & - & $?^{\circ}{ }^{\circ}$ \\
\hline$\lambda$ & $-\dagger$ & $-\dagger \dagger$ & 0 & + & $? \dagger \dagger$ \\
\hline$\pi$ & $-\dagger$ & $-\dagger \dagger$ & 0 & + & $?+\dagger$ \\
\hline$\rho_{i}, i=u, r$ & 0 & + & 0 & - & - \\
\hline$\sigma$ & 0 & + & 0 & - & - \\
\hline$c_{i}, i=u, r, x$ & + & + & 0 & - & - \\
\hline$\phi$ & - & + & - & - & - \\
\hline$\delta$ & 0 & + & - & - & - \\
\hline$k$ & 0 & + & - & - & - \\
\hline$\beta$ & 0 & + & 0 & + & + \\
\hline$y$ & 0 & 0 & + & - & - \\
\hline
\end{tabular}

* '+' (respectively, '-', '0') $\equiv$ given $\theta$, the function increases (respectively, decreases, remains unchanged) as the corresponding parameter (in column 1) increases.

** '+' (respectively, '-', '?') $\equiv$ the equilibrium value increases (respectively, decreases, moves in a direction that cannot be predicted) as the corresponding parameter (in column 1) increases.

- if $c_{r}<c_{x}$ and $c_{r}<c_{u}$, this sign is negative.

$\therefore$ if $c_{r}<c_{x}$ and $c_{r}<c_{u}$, this sign could become negative if $\rho_{r}$ was sufficiently close to $\rho_{u}$ and $\sigma$. $\cdots$ if $c_{r}<c_{x}$ and $c_{r}<c_{u}$ but the positive effect on the wage curve is maintained, this sign is negative.

$\dagger$ if $c_{r}<c_{x}$ and $c_{r}<c_{u}$, this sign is positive.

†† if $c_{r}<c_{x}$ and $c_{r}<c_{u}$, this sign could become positive if $\rho_{r}$ was sufficiently close to $\rho_{u}$ and $\sigma$.

t十† if $c_{r}<c_{x}$ and $c_{r}<c_{u}$ but the negative effect on the wage curve is maintained, this sign is positive.

$\ddagger$ if $c_{r}<c_{x}$ and $c_{u}<c_{x}$, this sign is positive.

㧊 if $c_{r}<c_{x}$ and $c_{u}<c_{x}$, this sign could become positive if $\sigma$ was sufficiently close to $\rho_{r}$ and $\rho_{u}$.

抹 if $c_{r}<c_{x}$ and $c_{u}<c_{x}$ but the negative effect on the wage curve is maintained, this sign is positive.

Note: If $k$ is proportional to $y$, the level of the latter does not affect $\theta$ nor $e$.

Table 2. Comparative statics. 


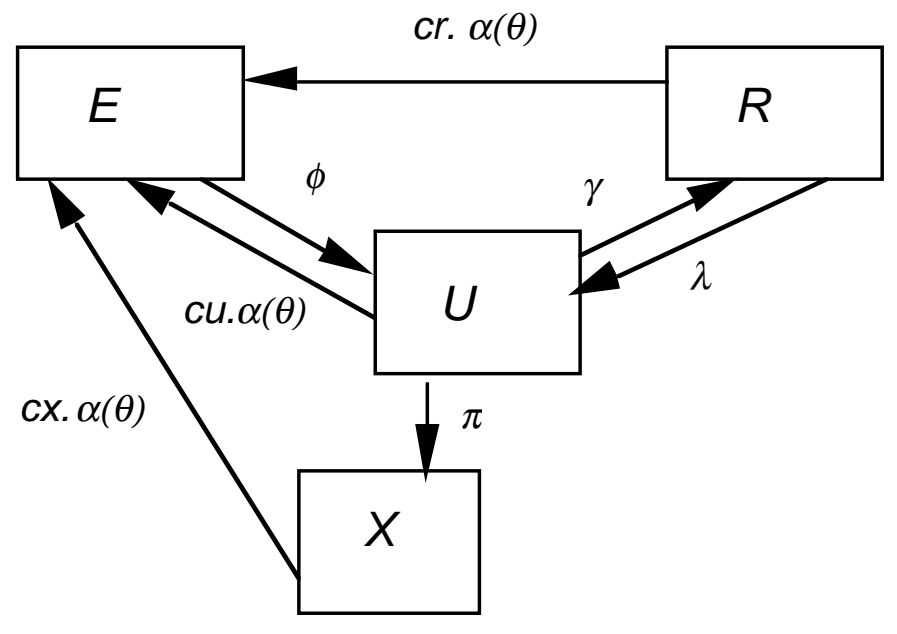

Figure 1: Labor market flows. 


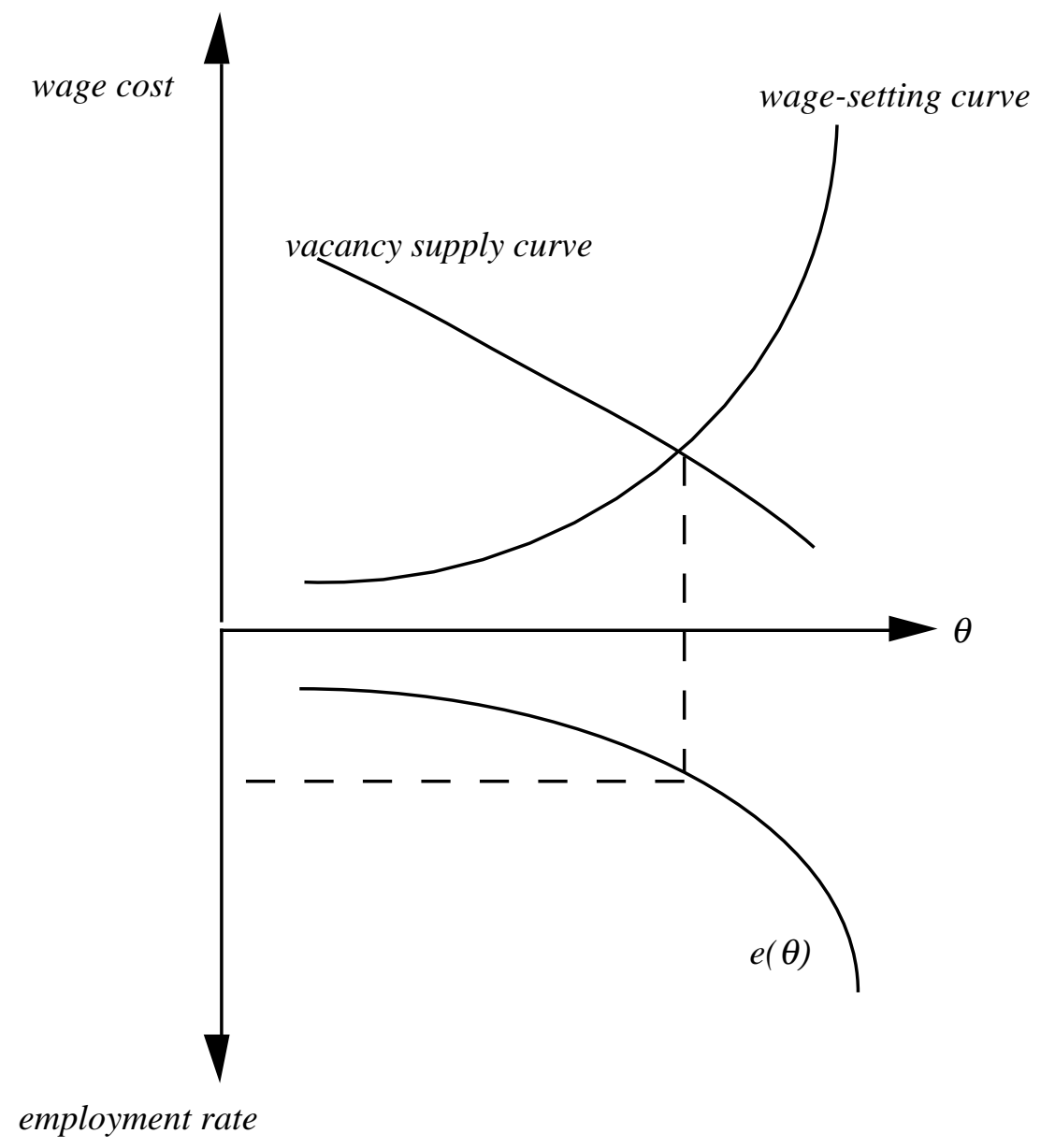

Figure 2: The steady-state equilibrium. 


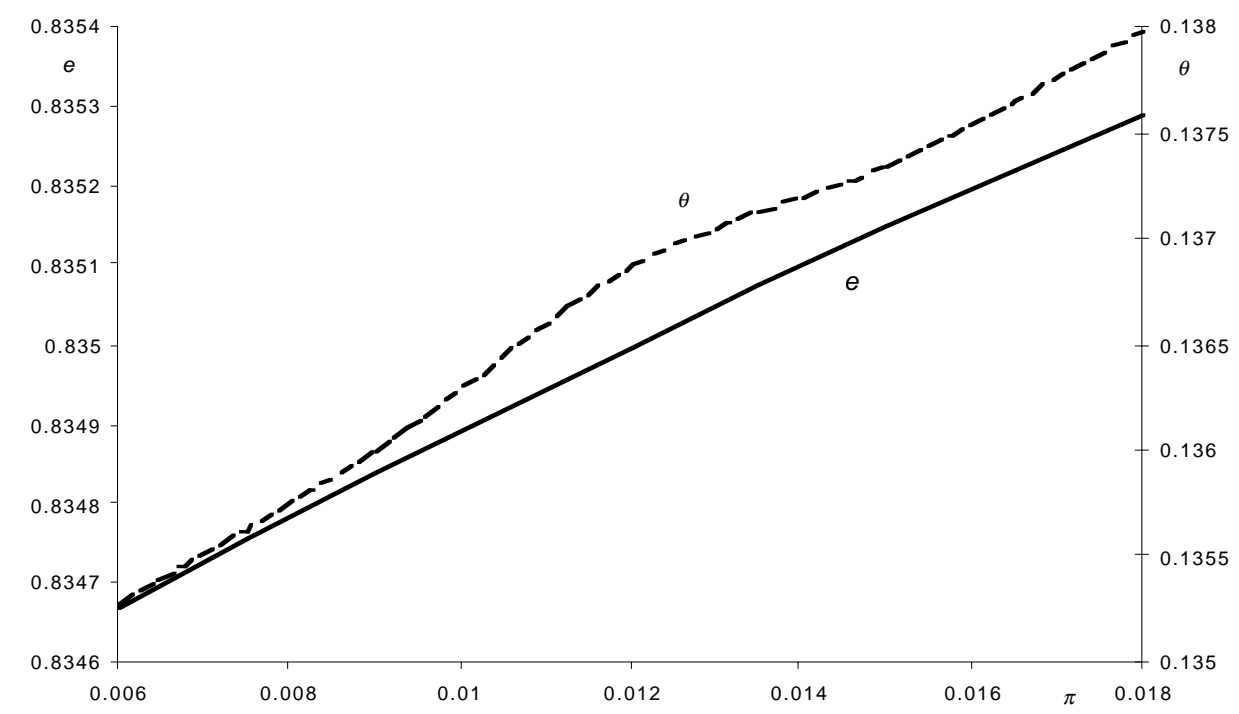

Figure 3: The simulated impact of the sanction rate, $\pi$, on the steady-state equilibrium values of tightness $\theta$ and on the employment rate $e$. 


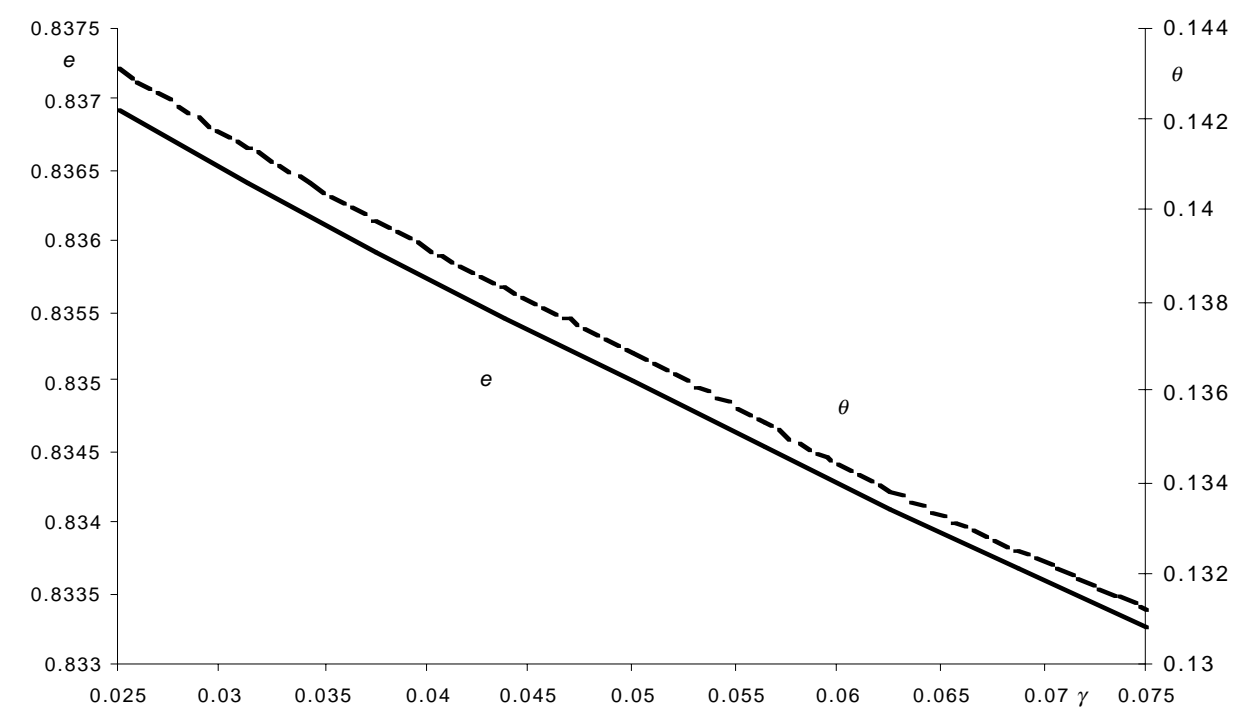

Figure 4: The simulated impact of the rate of entry into active programs, $\gamma$, on the steady-state equilibrium values of tightness $\theta$ and on the employment rate $e$. 


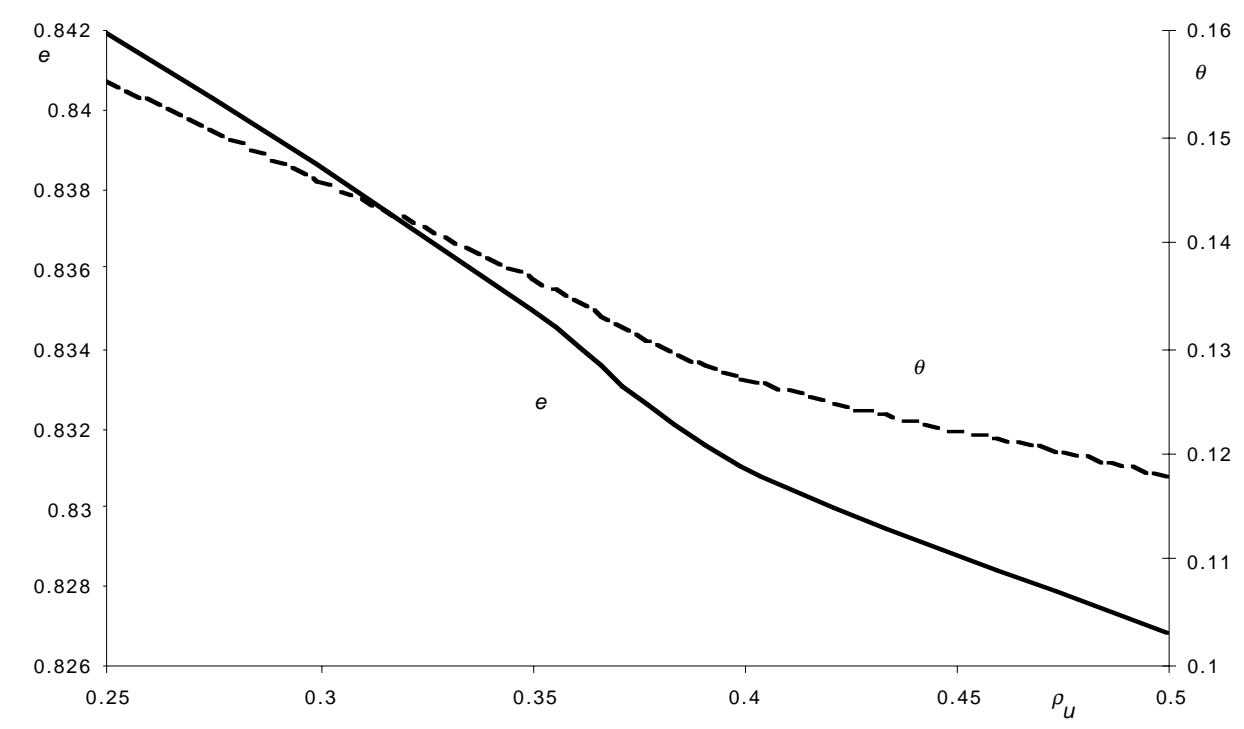

Figure 5: The simulated impact of the replacement ratio, $\rho_{u}$, on the steady-state equilibrium values of tightness $\theta$ and on the employment rate $e$. 